\title{
Teaching Optimization of Management Science Based on CNKI Platform
}

\author{
Jing Cao, Sijin Li, Haiqing Xu \\ School of Accounting, Dianchi College of Yunnan University, Kunming, 650000, China
}

Keywords: CNKI, Digitization, Management science.

\begin{abstract}
Digital learning can make up for the deficiencies of traditional learning to a certain extent, so that the breadth, depth and freedom of learning can be greatly improved. This paper introduced the basic circumstance of CNKI platform, and discussed the teaching optimization program and implementation situation of the management science course based on this platform and finally put forward some relevant suggestions.
\end{abstract}

\section{Introduction}

In the current wave of digital learning, college students have access to learning resources more easily on the Internet platform. Digital learning complements the shortcomings of traditional learning, which greatly improves the breadth, depth and freedom of learning. In this context, college teachers should not only impart knowledge in the classroom, but also train students' concept of lifelong learning and independent learning, and help students improve their information literacy.

Management is one of the core courses of business management major stipulated by the Department of higher education of the Ministry of education. It is a systematic study of the general laws, basic principles and general methods of management process. The purpose of the research is to find the objective law, sum up the general principles and methods of management and guide the practice of management. The introduction of CNKI into management studies can expand the field of learning and enhance teaching effectiveness.

\section{Basic Circumstance of CNKI Platform}

The concept of CNKI (China National Knowledge Infrastructure) was proposed by the world bank in 1998. CNKI informatization construction project aims at realizing the sharing, sharing and Value-added Utilization of the whole society knowledge resources. It was initiated by China Tsinghua University and Qinghua Tongfang. It was founded in June 1999. CNKI engineering group, after years of efforts, the independent development of technology and the digital library has the international leading level, built the world's largest amount of text information of the CNKI digital library ", and officially launched the construction" China knowledge resources database "and CNKI grid resource sharing platform, through the industrialization operation, providing knowledge and information resources the rich and the most effective dissemination of knowledge and digital learning platform for efficient sharing of knowledge resources the whole society.

CNKI large-scale integration of knowledge information resources, improve the comprehensive utilization of resources and the overall value of the value of knowledge resources construction; Internet spread and value-added service platform, resource sharing, digital learning, knowledge innovation and information technology conditions for the whole society. 


\section{Teaching Optimization Program and Implementation Situation of Management Science Course Based on CNKI}

Promote and Advertise the CNKI and Its Usage Method to Teachers and Students. On one hand, we should extend the application of CNKI in teaching, especially in the preparation of lessons. On the other hand, we will introduce the basic situation and methods of using CNKI platform for students. Specifically, we first introduce students to the CNKI platform includes database resources: journals, papers, dissertations and conference papers, newspapers, statistical data, CNKI platform contains tools: CNKI E-learning, standard terminology, academic trend search, concept search; next to students to demonstrate CNKI retrieval platform retrieval method with the final layout three key requirements for students to practice, students are required to master the basic use of CNKI.

Optimization of Lesson Preparation Based on CNKI Platform. Management is a practice oriented science, which needs to be constantly updated and perfected according to the development of the times and the needs of practice. CNKI provides plenty of teaching materials for teachers when they prepare lessons. These materials enrich the content of teaching, but also reflects the teaching with the times. Taking the chapter of human resources management during management as an example, this paper expounds how to prepare for teaching based on CNKI platform. With the help of "teaching for the academic trend of search" and "academic focus". Teachers in lesson preparation can first use of CNKI's "academic trend search" to understand the research field of human resource management in the current academic attention, attention to user, so the research on this field has an overall grasp. The following figure shows the academic attention of human resource management.

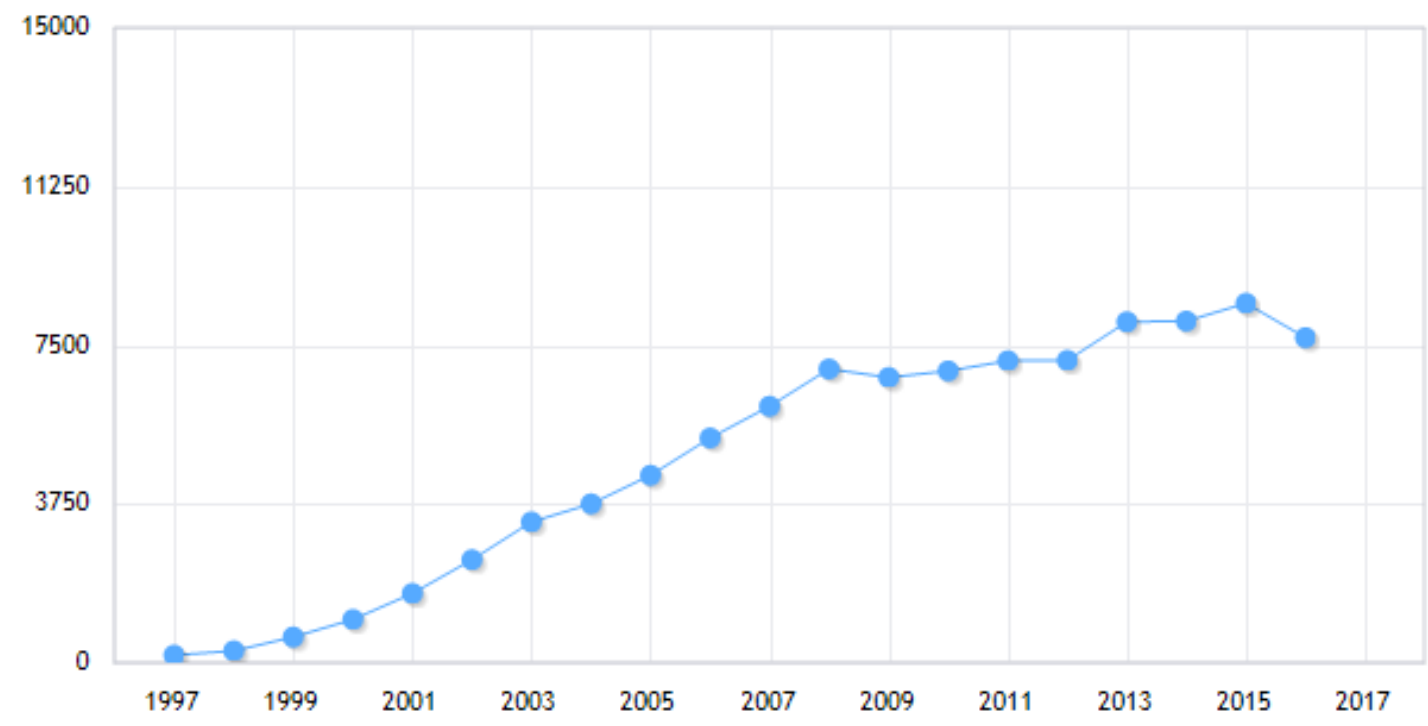

Figure 1. Academic attention of "human resource management"

Through the academic attention, we can detect the influential classical documents in the field of human resource management research. 
Table 1. Statistical table of cited literatures of human resource management

\begin{tabular}{|c|c|c|c|}
\hline Number & Literature name & Authors & Cited times \\
\hline 1 & $\begin{array}{l}\text { Research on competency model evaluation of top } \\
\text { managers in enterprises (2002) }\end{array}$ & $\begin{array}{lr}\text { Shi Kan, Wang } \\
\text { Jicheng, } \\
\text { Chaoping }\end{array}$ & 1752 \\
\hline 2 & Recent advances in competency research (2003) & $\begin{array}{l}\text { Lifeng } \quad \text { Shi } \\
\text { Zhong. }\end{array}$ & 1126 \\
\hline 3 & $\begin{array}{l}\text { Evaluation structure and method of job satisfaction } \\
\text { (2001) }\end{array}$ & $\begin{array}{l}\text { Lu Jia, Shi, Yang } \\
\text { Jifeng }\end{array}$ & 981 \\
\hline 4 & $\begin{array}{l}\text { Background characteristics of managers and over } \\
\text { investment behavior of enterprises (2009) }\end{array}$ & $\begin{array}{l}\text { Jiang Fuxiu, I } \\
\text { Shihiro, Su Fei, } \\
\text { Huang Lei }\end{array}$ & 835 \\
\hline 5 & Psychological contract in Organization (2001) & $\begin{array}{l}\text { Chen Jiazhou, } \\
\text { Ling Wenquan, } \\
\text { Liluo square }\end{array}$ & 739 \\
\hline 6 & $\begin{array}{l}\text { A study on the influence of employees' personal } \\
\text { characteristics on organizational commitment and } \\
\text { turnover intention (2003) }\end{array}$ & Cuixun & 645 \\
\hline 7 & How to motivate knowledge workers (1999) & $\begin{array}{l}\text { Peng Jianfeng, } \\
\text { Zhang Wangjun }\end{array}$ & 633 \\
\hline 8 & $\begin{array}{l}\text { Task performance and contextual performance two } \\
\text { factor performance model validation (2003) }\end{array}$ & $\begin{array}{l}\text { Wang Hui, Li } \\
\text { Xiaoxuan, Luo } \\
\text { Shengqiang }\end{array}$ & 554 \\
\hline 9 & $\begin{array}{l}\text { Research on performance management function and } \\
\text { performance evaluation system (2002) }\end{array}$ & $\begin{array}{l}\text { Sheng Yunhua, } \\
\text { Zhao Hongzhong }\end{array}$ & 510 \\
\hline 10 & $\begin{array}{l}\text { Analysis of the current situation of human resource } \\
\text { management theory (2005) }\end{array}$ & $\begin{array}{lr}\text { Shi, } & \text { Wang } \\
\text { Jicheng, } & \text { Li } \\
\text { Chaoping } & \end{array}$ & 494 \\
\hline
\end{tabular}

In addition, we can find the subject name, the main knowledge points, the heat value and the main document number of the research subject through the subject academic hot spot. The CNKI platform also supports hot topics according to field retrieval, based on the author in the accounting profession as an example, through the search, I found the research involving human resources management in accounting disciplines include human resource accounting, human resource cost accounting, human resource accounting measurement and other fields. In this way, we can not only grasp the hot spots and trends of the research field in general, but also be able to prepare the curriculum more specifically.

Enrich the teaching materials by means of literature retrieval. Teachers in preparing lessons with "theme", "title" and "Keywords" in "Journal", "Master Thesis", "meeting" and "newspaper" in the literature retrieval, to enrich the teaching materials, teaching materials reflect the timeliness. By searching, not only can get the empirical analysis of the case, but also to understand the latest developments in the field of theory and practice, to search in the Journal CSSCI via the "title" form, can obtain the authoritative research results in this field, the related research results such as green HPWS, human resource management, strategic human resource management. At the same time, we can search research reviews and get a more intuitive understanding of the research trends in a certain field. Through the review of articles can be learned "human resources management" and "human resources" and "human resources development" and "human capital" and "performance management" and "labor relations" will continue to be a period of time in the future China human resources research hot spots; and reflect the efficiency and justice idea, innovation driven development strategy of the salary "management "training" and "staff management "and" 
management" and "corporate culture "and" knowledge workers "and" the new generation of migrant workers" and "innovation "and" economic development "will also become a hot spot in the research of human resources during the period.

Treat CNKI as the Important Auxiliary Tools of Reading, Writing and Discussing of Students. "Management" teaching usually includes "guide, read, write, discuss" four links, teachers bear the main link is "guide", that is, guide students to read classics. Students need to complete the reading, writing, and discussion sessions.

Reading, reading classics, read good books, good reading. The teacher usually lists of classic books, in addition, in the era of information explosion how to obtain high quality in the most efficient way of information becomes especially critical, while CNKI is a high-quality information platform. Write, write experience, and write small papers. Reading and writing complement each other and promote each other. Through reading and writing, lay a solid foundation, and then lead students to identify problems and solve problems. Reading and writing are the premises of "discussion", and the most taboo of "talk" is "empty talk", which must be subject and focus, and based on sufficient reading of classical literature.

The same as in the teaching of "human resources management" section as an example, teaching students to take the group as a practical work choice of human resource management, through the CNKI search platform to collect data to illustrate the practical work of the enterprise human resources management with body expansion. On the one hand, the study group can choose according to their own interests and hobbies, and on the other hand, students can have a better understanding of knowledge through the process of retrieval. Take the "training" function of human resource management as an example through classroom teaching, students can only understand the content, steps, effect evaluation and other knowledge of training. Through the CNKI platform retrieval, data collection and collation of students around the problem, thus provides a new perspective and argument class discussion, the students in the classroom discussion joined the "MOOC era of training under the new development, staff training and risk investment analysis" as a new topic, so that students in the discussion no longer is from theory to theory, is no longer "feel" speak generally, which greatly improves the quality of discussion.

Learning Expansion Platform of Students Based on CNKI. The teaching capacity of traditional teaching will be affected by class hours and other factors, and teachers often need to arrange extra-curricular reading to help students expand their knowledge. CNKI provides a good platform for students' learning development. Teachers can assist students in learning through keyword prompts. "Human resources management" in classroom teaching, teachers can be carried out according to the professional characteristics and the keywords that a hot research field, such as "HRBP", "mobile HR", "Internet plus human resource management", "big data + human resources management".

\section{Teaching Effect}

After introducing CNKI into the teaching, students generally reflect that CNKI database resources can provide rich learning resources, and these resources are more complete and authoritative than ordinary network resources. Especially for those students who are going to take postgraduate courses in academic research, they reflect that CNKI provides a broader view and a higher platform for further study in the future.

\section{Relevant Suggestions}

Make Students Really Understand the Meaning of Using CNKI in Learning. CNKI database resources can provide a wealth of teaching materials for teachers, as well as an authoritative platform for students to expand their knowledge. In teaching, it is necessary to let students really understand the meaning of using CNKI, otherwise it will make the students feel more burden. Therefore, one should use the specific method of CNKI patient in teaching, so that students can skillfully use 
retrieval platform and various learning tools, on the other hand to stimulate students' enthusiasm for learning, to guide students to establish the concept of lifelong learning. While using CNKI, students are encouraged to contribute to CNKI and express their academic views and opinions.

Strengthen Publicity. We found the undergraduate students generally only in writing academic papers in the process of teaching and thesis will use CNKI, use the rest of the CNKI is not much, some students before writing papers hadn't even heard of CNKI. Based on the above circumstances, it is suggested that CNKI strengthen publicity and promotion, so that more teachers and students can fully understand CNKI, master the use of CNKI retrieval function and the use of various tools, and more benefit from CNKI. Specifically, CNKI can strengthen exchanges and cooperation with universities, through lectures, seminars, training and other forms, CNKI and university teachers and students together to explore resources and tools in the further application of teaching.

Strengthen the Construction of Mobile Platform. According to the 2017 China Internet Network Information Center (CNNIC) fortieth "development China Internet Statistics Report" released by the end of June 2017, Chinese users reached 751 million, accounting for 1/5 of the total number of global Internet users. Internet penetration rate of $54.3 \%$, exceeding the global average of 4.6 percentage points. Among them, the scale of China's mobile phone users reached 724 million, the use of mobile Internet users in the proportion of 96.3\%, in line with this trend, CNKI should strengthen the construction of mobile platforms. At present, CNKI has opened a mobile phone network, WeChat opened the public number, the new CNKI collaborative research platform OKMS to achieve a variety of internal and external knowledge resources agency one-stop discovery and acquisition, real-time collaborative research support multimedia, multi modes, multi terminal cooperative communication, support research and innovation team, CNKI E-Study3.2.1 and digital learning a new research platform for the majority of researchers opened a new research learning experience. It is worth further thinking how to make more people understand, be familiar with and be willing to choose and use CNKI mobile terminal in many learning platforms.

\section{References}

[1] Zhang Haoyu, Fang Hongjun. The Basic Situation, Hot Topics and Its Evolution of The Domestic Research on Human Resources in The 21st Century- Bibliometric Analysis and Visualization of Literature Based on "Human Resources Development of China” [J]. Human Resources Development of China, 2015(5): 23-32.

[2] Zhou Jian, He Xing. Study on the Evaluation on the Core Journals of Management Science Based on Principle Component Analysis [J]. Journal of Library and Information Science, 2015, 25(3): 127-130+136.

[3] Yu Yun. The Implementation of Case Teaching during the Process of Managements Teaching [J]. Value Engineering, 2013(33): 204-205.

[4] Ding Fuhu. The Basic Characteristics of Highly Cited Papers in the Field of Science and Technology Management Based on the Quantitative Analysis of Documents in Cnki [J]. Science and Technology Management Research, 2016(8): 258-266. 